\title{
EARLY POSTSETTLEMENT PREDATION ON THREE REEF FISHES: EFFECTS ON SPATIAL PATTERNS OF RECRUITMENT
}

\author{
Mark A. Steele ${ }^{1}$ And Graham E. Forrester \\ Department of Biological Sciences, University of Rhode Island, 100 Flagg Road, Kingston, Rhode Island 02881 USA
}

\begin{abstract}
Marine organisms suffer extensive mortality just after settling from the plankton, yet, little is known about the role that predators play in causing this mortality. We estimated the rates of predation in the first $24 \mathrm{~h}$, and the first week, after settlement in three species of reef fish. To estimate these rates we compared the accumulation of recent settlers on plots from which predators were excluded (by caging) to settlement on unmanipulated control plots. The magnitude of predation varied greatly among our three focal species, even though they are ecologically similar (all are small gobies that inhabit the reef/sand interface). Within $24 \mathrm{~h}$ of settlement, predators apparently killed $92 \%$ of settled blackeye gobies, $26 \%$ of bridled gobies, and $6 \%$ of goldspot gobies. Within a week, predation had significantly reduced recruitment of all three species and was the main cause of death during this period.

We also tested whether predation on new settlers affected spatial patterns of abundance at two scales. At small scales (areas separated by tens of meters) the distortion of settlement patterns increased as the magnitude of postsettlement predation increased. Blackeye gobies suffered intense, density-dependent, postsettlement predation that completely obscured spatial patterns of settlement and larval supply. Moderate, density-independent predation on bridled gobies only moderately distorted spatial patterns of settlement and larval supply. Low, density-independent predation on goldspot gobies did not greatly alter patterns of settlement of this species, but unlike the other two species, settlement of goldspot gobies was not correlated with larval supply at small scales. At a larger spatial scale (sites separated by hundreds to thousands of meters), predation failed to distort significantly the input rates of any of the three gobies, and differences between sites in larval supply and settlement were still apparent up to a week after settlement. Overall, our results indicate that predation immediately following settlement can distort spatial patterns of input extremely rapidly, but the degree to which settlement patterns are distorted may be highly species- and scaledependent.
\end{abstract}

Key words: Coryphopterus; Gnatholepis; gobies; larval supply; population regulation; postdispersal mortality; predation; recruitment; reef fishes; spatial patterns of abundance.

\section{INTRODUCTION}

In organisms that have a relatively sedentary stage and dispersive propagules (e.g., many fishes, invertebrates, and plants), the size of local populations of the sedentary stage is set mainly by a dynamic balance between input of propagules and their subsequent loss via death. It is widely appreciated that variation in the rate of supply of propagules can cause populations to vary in size (Crawley 1992, Olafsson et al. 1994, Caley et al. 1996, Menge 2000), and processes that determine the rates of input of propagules into populations have been increasingly scrutinized (e.g., Kingsford and Choat 1986, Farrell et al. 1991, Herrera et al. 1994, Milicich 1994, Bertness et al. 1996, Sponaugle and Cowen 1997, Shanks et al. 2000, Wenny 2000). These processes may, however, be relatively unimportant in setting population size if postdispersal mortality se-

Manuscript received 7 August 2000; revised 29 May 2001; accepted 3 August 2001; final version received 10 September 2001.

${ }^{1}$ E-mail: steele@uri.edu verely distorts the patterns of input (Connell 1985). The extent to which patterns of input actually are distorted in marine systems is not well known, because few studies have simultaneously measured rates of input and any resulting variation in population size (e.g., Minchinton and Scheibling 1991, Bertness et al. 1992, Forcucci et al. 1994, Herrnkind and Butler 1994, Eggleston and Armstrong 1995, Schmitt and Holbrook 1999). If studies of terrestrial plants (e.g., Brown and Heske 1990, Crawley 1992) are any guide, the distortion of patterns of propagule input in marine systems could be dramatic.

The few studies in marine systems that have simultaneously measured rates of propagule input and subsequent variation in population size have usually not investigated the causes of postsettlement mortality. As a result, we have not identified which processes are most important in altering the relationship between population size and the rate of input of propagules in marine systems. One process that may be particularly important in modifying patterns of propagule input is predation (Crawley 1992, Eggleston and Armstrong 

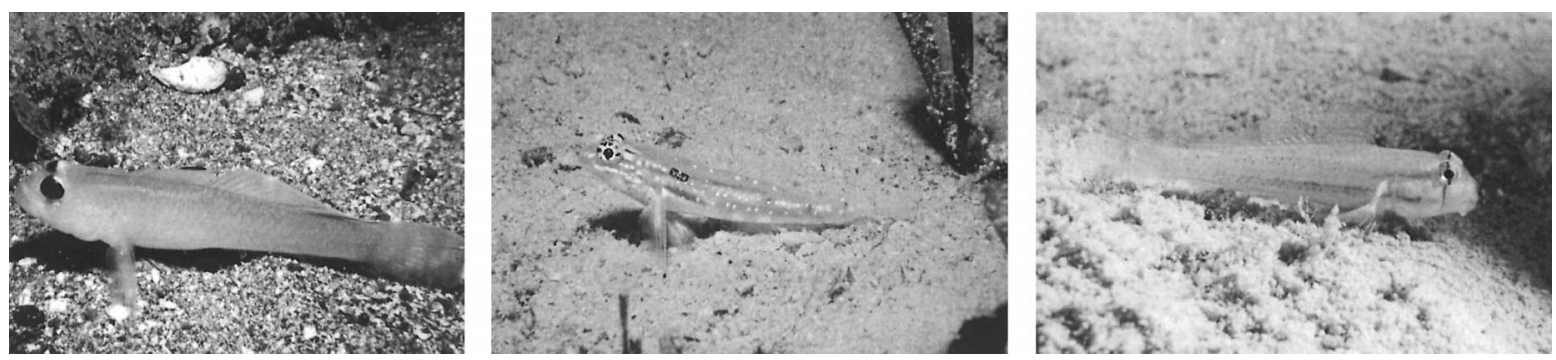

Plate 1. The three study species: (left) blackeye goby, (center) bridled goby, and (right) goldspot goby. All three individuals shown are adults. Note the three-digit, alphanumeric tag (visual implant tag from Northwest Marine Technology, Shaw Island, Washington) visible through the skin of the bridled goby. Left and center photographs by Mark Steele, right photograph by Morgan Bond.

1995, Steele $1997 a$ ), because it is often a major cause of postsettlement mortality (Connell 1961, Paine 1966, Carr and Hixon 1995, Steele 1996, Hixon and Carr 1997, Hunt and Scheibling 1997). The impact of predation on the relationship between population size and patterns of propagule input is, however, relatively unexplored (but see Eggleston and Armstrong 1995, Steele 1997a).

In this study, we evaluated the extent to which predation that occurred within a day or week of larval settlement altered spatial patterns of abundance generated by propagule input (larval supply and settlement). We focused on this early-postsettlement period because patterns of settlement are often estimated from the density of settlers still surviving days or weeks after settlement actually occurred. These estimates of settlement may bear little resemblance to the actual patterns of settlement if predation during the period intervening between settlement and census is intense and variable (Warner and Hughes 1988). Indeed, it is widely believed that postsettlement mortality in marine organisms is at its maximum just after settlement (reviewed in Hixon 1991 and Hunt and Scheibling 1997; see also Doherty and Sale 1985, Sale and Ferrell 1988, Schmitt and Holbrook 1999; but see Caley 1998). In reef fishes, it is also generally assumed that predators are the main cause of postsettlement mortality (reviewed in Hixon 1991); but other than one preliminary study by Doherty and Sale (1985), the rates of predation on newly settled reef fishes have not been measured. Consequently, the extent to which predators distort patterns of settlement in marine organisms, and particularly in reef fishes, is not well known.

Our general goal was to evaluate the extent to which early postsettlement predation distorted spatial patterns of larval input in three reef fishes. Distortion can occur if the mortality inflicted by predators is density dependent. It can also occur when predation is density independent if the mortality inflicted varies in space. Our specific goals were, therefore, to (1) estimate the magnitude of predation over the first $24 \mathrm{~h}$ after settlement and determine whether this predation was density dependent; (2) estimate the rate of mortality over the first week after settlement and determine how much of this mortality was caused by predators; (3) determine the degree to which predation distorted the relationship between recruitment and settlement or larval supply; and (4) evaluate whether the degree of distortion of the relationship between recruitment and settlement or larval supply changed with spatial scale. We were interested in the issue of scale dependence because it has been hypothesized that postsettlement processes are more constant at large scales than are the oceanographic processes that drive larval supply and settlement (e.g., Tolimieri 1995, Caselle and Warner 1996, Hunt and Scheibling 1997). Postsettlement mortality should, as a result, have a diminishing influence on patterns in abundance as we increase our scale of observation. We tested these ideas using three different species of reef fish in two different systems (one tropical and one temperate) to evaluate the generality of our findings.

\section{METHODS}

\section{Study system and study species}

We studied three ecologically similar species of goby (Gobiidae). In the temperate eastern Pacific we studied the blackeye goby (Coryphopterus nicholsii), and in the tropical western Atlantic we studied the bridled goby (Coryphopterus glaucofraenum) and the goldspot goby (Gnatholepis thompsoni). All three species occur in the same microhabitat: areas of mixed reef and sand, which are found primarily at the edge of coral or rocky reefs. In this microhabitat, the gobies shelter in crevices and burrows and forage on invertebrates. Each species was studied at two study sites that were chosen because they were likely to differ in the supply of larval gobies and in the assemblage of predators.

The two study sites for blackeye gobies were at Santa Catalina Island $\left(33^{\circ} 27^{\prime} \mathrm{N}, 118^{\circ} 29^{\prime} \mathrm{W}\right)$, off the coast of southern California, USA. At this site, suitable goby habitat consists primarily of large rocky reefs hundreds of meters in extent, which are isolated by stretches of bare sand (see Carr 1994 and Anderson 1994 for more detailed descriptions). The two reefs we used, Big Fisherman Cove (BFC) and Chalk Cove, both provide sim- 
ilar low-relief, macroalgae-covered rocky habitat. The reefs are separated by $\sim 400 \mathrm{~m}$, which is sufficient to prevent migration among the sites by gobies and their predators. We anticipated that larval supply might differ between the two sites because there appears to be an eddy within BFC (Anderson and Sabado 1995; M. A. Steele, personal observations), but Chalk Cove is outside of this eddy and exposed to more direct currents (M. A. Steele, personal observations).

The two sites at which we studied the tropical gobies were near Lee Stocking Island $\left(23^{\circ} 46^{\prime} \mathrm{N}, 76^{\circ} 10^{\prime} \mathrm{W}\right)$ in the Bahamas. Although small patch reefs can be found in this area, the majority of goby habitat is on large (hundreds of meters) areas of continuous backreef in shallow water. These reefs are composed mainly of limestone hardpan, rubble, live and dead hard corals, gorgonians, and sponges. Reefs are separated from others by expanses of sand and seagrasses. Larval reef fishes are most abundant offshore and are delivered to our sites when offshore water masses are forced through narrow channels into the backreef by tidal flow (Thorrold et al. 1994). The two reefs we used, Rainbow Reef and Windsock Reef, are separated by $\sim 10 \mathrm{~km}$ and receive water forced through channels that are $\sim 12 \mathrm{~km}$ apart (Stoner et al. 1996). Since patterns of larval supply in this area are coherent only over scales of up to $\sim 1.5 \mathrm{~km}$ (Thorrold et al. 1994), our two sites probably experience different regimes of larval supply.

Gobies in the Bahamas and at Santa Catalina are exposed to quite different assemblages of predators. At Santa Catalina, the predators we most commonly observe consuming recently settled blackeye gobies are kelp bass (Paralabrax clathratus, family Serranidae) and rock wrasse (Halichoeres semicinctus, family Labridae), but we did not census predators at our two study sites to document their abundance. In the Bahamas, newly settled gobies are exposed to a larger group of potential predators, but our observations indicate that most losses are inflicted by slippery dicks (Halichoeres bivittatus), an extremely abundant generalist microcarnivore, and two other wrasses, H. garnoti and Thalassoma bifasciatum. Surveys using SCUBA showed that slippery dicks were about equally abundant at our two sites, but most other predator species were more abundant at Windsock reef than at Rainbow reef.

The three gobies that we studied all produce planktonic larvae that hatch from demersal eggs, but the duration of larval life differs among species. Larvae settle after $\sim 1$ mo in bridled gobies (Sponaugle and Cowan 1994), 1.5-3.5 mo in goldspot gobies (Sponaugle and Cowan 1994), and $\sim 2.5$ mo in blackeye gobies (M. A. Steele and G. E. Forrester, unpublished data). Size at settlement also varies among the species: bridled gobies settle at $6-10 \mathrm{~mm}$, goldspot gobies at $8-12 \mathrm{~mm}$, and blackeye gobies at $15-25 \mathrm{~mm}$ standard length (SL) (M. A. Steele and G. E. Forrester, unpublished data.) Adults of all three species are small, reaching maximum standard lengths of $\sim 55 \mathrm{~mm}$ for the two tropical species and $\sim 90 \mathrm{~mm}$ for the temperate species. There are no ontogenetic shifts after settlement: all demersal stages live in the same microhabitat, forage in the same manner, and are very site-attached. (Adults rarely move more than a few meters and juveniles move even less [M. A. Steele and G. E. Forrester, unpublished data].) Despite the co-occurrence of age classes and the resulting potential for interaction between settlers and older individuals, settlement of all three species is unaffected by the density of older conspecifics or likely interspecific competitors (Steele 1997a, Steele et al. 1998, Forrester 1999; B. Evans and M. A. Steele, unpublished data).

\section{Tests for cage artifacts}

To evaluate the effects of predation we used cages to manipulate the presence of predators. We tested for potential artifacts of caging in separate experiments done in 1993 at Santa Catalina and in 1997 in the Bahamas. In both cases, we compared settlement or recruitment on plots that were enclosed in complete cages, had no cage, or were enclosed in partial "control" cages that mimicked the structure of complete cages but allowed predators access to the plot. If there were no cage artifacts, then the density of recent settlers on cage-controls and uncaged plots should not differ.

These experiments were done on small $(0.9 \times 0.9$ m) artificial reefs constructed $10-30 \mathrm{~m}$ off nearby natural reefs on sandy plains. Cages were $0.9 \times 0.9 \times 0.6$ $\mathrm{m}$ high and were built of plastic netting (5-mm mesh in the Bahamas and 19-mm mesh at Santa Catalina) on polyvinyl chloride (PVC) pipe frames. The partial cages used at Santa Catalina lacked just the lower half of one side, whereas those used in the Bahamas lacked two sides. The artificial reefs were built of a standard number and size distribution of rocks at Santa Catalina and of five large queen conch (Strombus gigas) shells in the Bahamas. The experiments were conducted at only one site at both locations. In the Bahamas, we used five spatial blocks that each contained one replicate of the three treatments $(n=5)$. At Santa Catalina, we used three spatial blocks that each contained 12 reefs: 2 uncaged reefs, 5 partially caged reefs, and 5 fully caged plots (i.e., total $n=6,15$, and 15) and these were randomly assigned to positions within each block. Recent settlers were collected daily in the Bahamas, but blackeye goby recruits at Santa Catalina were only collected once, $25 \mathrm{~d}$ after the start of the experiment.

We analyzed the results of the experiments on cage artifacts with two-way analysis of variance (ANOVA); the factors were treatment (cage, "cage control," and uncaged) and block. Block was treated as a fixed factor at Santa Catalina because blocks varied in depth and distance from the reef, whereas block was treated as a random factor in the Bahamas where there were no obvious systematic differences among blocks. Since 
TABle 1. Experimental design.

\begin{tabular}{|c|c|c|c|}
\hline \multicolumn{4}{|l|}{ A) Treatments } \\
\hline $\begin{array}{l}\text { Treatment } \\
\text { Code }\end{array}$ & Parameter estimated & Predator treatment & $\begin{array}{c}\text { Frequency of } \\
\text { collection }\end{array}$ \\
\hline A & actual settlement & excluded (caged) & daily \\
\hline $\mathrm{B}$ & apparent settlement & present (uncaged) & daily \\
\hline $\mathrm{C} \dagger$ & recruitment without predators & excluded (caged) & weekly \\
\hline $\mathrm{D} \dagger$ & recruitment with predators & present (uncaged) & weekly \\
\hline $\mathrm{E}$ & larval supply & excluded (caged) & weekly \\
\hline
\end{tabular}

B) Effects

\begin{tabular}{|c|c|c|}
\hline Quantity estimated or question addressed & Estimate & $\begin{array}{l}\text { Statistical } \\
\text { comparison }\end{array}$ \\
\hline Effect of predators on settlement & $\mathrm{B}-\mathrm{A}$ & B vs. A $\neq$ \\
\hline Rate of predation within $24 \mathrm{~h}$ of settlement & $1-\mathrm{B} / \mathrm{A}$ & none \\
\hline Is predation density dependent? & (see Methods) & (see Methods) \\
\hline Effect of predators on recruitment & $\mathrm{D}-\mathrm{C}$ & D vs. C $\$$ \\
\hline Mortality in first week after settlement & $1-\mathrm{D} / \mathrm{A}$ & D vs. $A \ddagger$ \\
\hline Proportion of mortality in first week caused by predators & $(\mathrm{C}-\mathrm{D}) /(\mathrm{A}-\mathrm{D})$ & none \\
\hline Does predation distort spatial patterns of settlement? & $r^{2}$ & $\begin{array}{l}\text { regress } \mathrm{B} \text { vs. A, } \\
\text { regress } \mathrm{D} \text { vs. A }\end{array}$ \\
\hline Does larval supply drive settlement? & $r^{2}$ & regress $\mathrm{A}$ vs. E \\
\hline Does larval supply drive recruitment? & $r^{2}$ & $\begin{array}{l}\text { regress } \mathrm{B} \text { vs. } \mathrm{E} \\
\text { regress D vs. } \mathrm{E}\end{array}$ \\
\hline
\end{tabular}

Notes: Treatments A-D were on randomly selected $1.5 \times 1.5 \mathrm{~m}$ plots on natural reefs where the habitat had not been altered, whereas treatment $\mathrm{E}$ was a $0.9 \times 0.9 \times 0.6 \mathrm{~m}$ high cage containing standardized settlement habitat placed $10 \mathrm{~m}$ off the natural reef (see Methods: Main experiment: Experimental design for more details).

$\uparrow$ These treatments were not used for the blackeye goby.

† For comparisons 1-3, a priori comparisons were used in conjunction with ANOVA (see Methods: Main experiment: Estimating rates of predation).

there was no replication of treatments within blocks in the Bahamas, the test for treatment effects used the residual mean-square error term in calculating $F$ values. We were primarily interested in two comparisons, cage control vs. uncaged plots and cage control vs. caged plots, and so used a priori (planned), pairwise contrasts to make these comparisons (see Underwood 1997). This is the appropriate, and most powerful, approach to test hypotheses of this sort, but readers unfamiliar with a priori comparisons should bear in mind that the $F$ and $P$ values for these pairwise comparisons will differ from those reported for the overall treatment effect in the ANOVA.

\section{Main experiment}

Experimental design.- In the Bahamas, our main experiment lasted for $3 \mathrm{wk}, 11$ August-1 September 1997. At Santa Catalina, the experiment was carried out for one week, 24 June-1 July 1996. These periods coincided with seasonal peaks in settlement. During the experiments, we measured settlement and recruitment on plots exposed to and free of predators, and we also measured a proxy for larval supply. We used five treatments in the Bahamas but two of these were not used at Santa Catalina (Table 1). The first four treatments were: (treatment A) a predator-free plot from which we collected settlers daily ("actual settlement"); (treatment B) a predator-exposed plot with settlers collected daily ("apparent settlement"); (treatment C) a predator-free plot with recruits collected weekly ("recruit- ment without predators"); and (treatment D) a predator-exposed plot with recruits collected weekly ("recruitment with predators"). Treatments C and D were not used at Santa Catalina. The final treatment (E) was a "larval collector" (our index of larval supply), which was a caged unit of standardized settlement habitat placed on sand flats $10 \mathrm{~m}$ off the natural reefs. Our experimental design included five replicate sampling stations (blocks) at each of two sites. The sampling stations were arrayed along the perimeter of both sites and each station contained one replicate of each treatment. In the Bahamas, plots within a station were 5$20 \mathrm{~m}$ apart, and stations were separated by $60 \mathrm{~m}$. At Santa Catalina, plots within a station were $10 \mathrm{~m}$ apart and stations were seperated by $30 \mathrm{~m}$.

Measuring settlement, recruitment, and larval supply.-_Plots on the reef were $1.5 \times 1.5 \mathrm{~m}$ and were either enclosed in a cage or left unmanipulated except for small metal stakes placed to mark the corners. The cages used to exclude predators from plots at Santa Catalina were built of nylon netting (9.5-mm mesh) on a $1.5 \times 1.5 \times 0.6 \mathrm{~m}$ high PVC pipe frame. The netting extended $\sim 0.2 \mathrm{~m}$ beyond the bottom of the frame and was attached to a galvanized steel chain, which weighted the netting and sealed the cage to the sea floor. The cages in the Bahamas were built of 5-mm mesh plastic netting on PVC pipe frames that were $0.9 \times 0.9 \times 0.6$ $\mathrm{m}$ high. Attached to the bottom of these cages was a $0.15 \mathrm{~m}$ wide skirt of $2-\mathrm{mm}$ nylon mesh netting, again weighted with galvanized chain to seal the cage to the 
sea floor. On predator-free plots at Santa Catalina, settlement was measured only inside the cages because recently settled blackeye gobies were rarely observed to move through the netting. In contrast, the two gobies in the Bahamas often used areas just outside of the cages and then retreated through the netting into the cage when threatened. Therefore, we measured settlement in the entire $1.5 \times 1.5 \mathrm{~m}$ plot, including the portion outside of the cage, because the plot boundary matched the greatest distance a recently settled goby would venture from the cage. If predators ate some settlers venturing into the part of the plot outside the cage, we will have underestimated the rate of predation in the Bahamas because our predator-exclusion treatment was not completely effective.

Settlement and recruitment were measured by collecting all recently settled gobies within the boundaries of each plot using hand nets. We collected all small juvenile gobies from the plots, including those we believed to be too large to be newly settled. In the laboratory we separated the juveniles collected into three age classes: $\leq 1 \mathrm{~d}$ postsettlement, $>1$ to $\leq 7 \mathrm{~d}$ postsettlement, and $>7 \mathrm{~d}$ postsettlement. These assignments were made using a combination of morphological features and body size and were validated by counting otolith growth rings to age a subsample of the juveniles (M. A. Steele, unpublished data).

In addition to evaluating the effect of predators on recruitment, we explored the influence of larval supply on patterns of settlement and recruitment. To do this we estimated the supply of larvae that were developmentally competent to settle by using "larval collectors." These were simply caged units of standardized settlement habitat placed $10 \mathrm{~m}$ off the edge of the reefs, to which larvae settled. They were caged to avoid any distortions of this index of larval supply that could be caused by predation after settlement. The "larval collectors" were identical to the caged treatments used in the test for cage artifacts described earlier. Because the collectors in the Bahamas rested on a sand bottom that contained variable densities of seagrass (mainly Thalassia testudinium), to standardize the habitat, we clipped off all seagrass at the level of the sand in a 1.5 $\times 1.5 \mathrm{~m}$ area. After collecting recently settled gobies each week, the grass was re-clipped and the cages scrubbed to avoid fouling (cages on plots on the reef were also scrubbed weekly). Of the fish collected weekly from the collectors, only those individuals judged to have settled during the previous week (based on the laboratory sorting protocol described earlier) were included in our estimate of larval supply.

In using the larval collectors as an index of larval supply, our assumption is that larvae settled onto them in proportion to their abundance in the water column. This assumption would be false if cues for settlement exist on scales larger than the collectors (e.g., depth or reef-related cues). If such a bias were present, our index of larval supply would probably be correlated with our estimate of settlement on the reef because the same cue would likely affect settlement on both types of plots. In this case, our estimate of the importance of larval supply in driving patterns of settlement would be inflated.

Estimating rates of predation.-We made specific contrasts between the predation treatments to estimate predation occurring within $24 \mathrm{~h}$ of settlement and over the first week following settlement (outlined in Table 1). Other contrasts were made to estimate mortality from all sources (including predation) during the first week after settlement, and then isolate the fraction of the weekly mortality that could be attributed to predation. These estimates are based on the assumption that predator-free plots from which settlers were collected daily measure the actual rate of settlement, because mortality from sources other than predation is negligible in the first $24 \mathrm{~h}$. This assumption seems reasonable because in thousands of hours of observation at these sites we have regularly observed predation but have never seen new settlers of any of the three species of gobies die from other causes.

Estimating predation rates by comparing uncaged and caged plots also assumes that the difference in settler density between caged and uncaged plots is due solely to predatory mortality. Differential settlement or recruitment could also arise if young gobies can detect predators and avoid areas where they are present. We cannot rule out this possibility, but it seems unlikely that settling larvae could detect a difference between predator-free and predator-exposed plots, because the predators are mobile and make only brief visits to any given plot. Aggregation to caged areas after settlement also seems unlikely because recently settled gobies are very sedentary (M. A. Steele and G. E. Forrester, personal observations). Coupled with our observation that predators regularly consume recently settled gobies that are not protected by cages, we think it is reasonable to attribute most of the difference between caged and uncaged areas to predation.

The results of the main experiment were analyzed using a three-factor ANOVA model. The model included terms for predation treatment, site, and station (nested within site), and the interaction between site and treatment. (The other two possible interactions could not be included since there was no replication of treatments within stations.) We considered site and treatment to be fixed factors and station to be a random factor. In these models, then, the "station" mean square was used as denominator for the $F$ statistic in the test of the main effect "site," whereas the residual (error) mean square was used for all other effects (Winer et al. 1991).

For the two species in the Bahamas there were four levels of predation treatment (treatments A-D in Table 1). As mentioned above, we designed the experiment to test three hypotheses by making three specific pairwise contrasts among these four predation treatments 
(see Table 1), so we used a priori planned comparisons to test those hypotheses (Underwood 1997). For the blackeye goby at Santa Catalina there was no need to use a priori comparisons because only two predation treatments (A and B) were included, and therefore the main effect in the ANOVA model is the appropriate test for a difference between them.

Testing whether predation distorts spatial patterns of larval supply and settlement.-We replicated all treatments spatially in blocks ("stations") 30-60 m apart so that we could test whether predation altered patterns in abundance established by propagule input (see Table 1). We used linear regression to test whether settlement and recruitment on the predator-exposed plots at a station (treatments B and D) were related to "actual settlement" at the same station (treatment A). If the two relationships (B vs. A and D vs. A) were tight, then predation did little to distort the spatial patterns of settlement measured at the scale of blocks. In the same manner, we tested whether spatial variation in larval supply drove patterns of settlement and recruitment by measuring the strength of the relationships between settlement or recruitment (treatments A, B, or D) and our index of larval supply (treatment E). For these regressions, we pooled the data from the two sites to allow stronger tests. Pooling seemed justifiable because analysis of covariance detected no difference in the slope of the relationships at the two sites in any case ( site $\times$ settler density or site $\times$ index of larval supply interactions: $P>0.24$ in all cases) and visual inspection of these data did not suggest any obvious differences in slopes between sites (see Figs. 5 and 7).

We also evaluated whether predation distorted patterns of larval supply or settlement at a larger scale, between the two sites separated by hundreds to thousands of meters. At this larger scale, distortion was tested by the interaction term between "site" and "treatment" in ANOVA. Note that even if there was some bias in our estimate of predation rates (for reasons discussed above), as long as any biases did not vary spatially, then our study should still provide a good test of the effects of predators on spatial patterns of recruitment.

Testing for density-dependent predation.-To test whether predation occurring within $24 \mathrm{~h}$ of settlement was density dependent, we regressed our estimate of predation at a station against the density of settlers at that station (treatment A). The per capita rate of predation occurring within $24 \mathrm{~h}$ of settlement was estimated as 1 - (apparent settlement/actual settlement); the per capita rate of predation occurring within a week of settlement was estimated as 1 - (recruitment with predators/recruitment without predators); and the per capita rate of mortality occurring within $7 \mathrm{~d}$ of settlement was estimated as 1 - (recruitment with predators/ actual settlement) (Table 1). Because we were not following known individuals over time, these estimates of mortality were probably more variable than the true

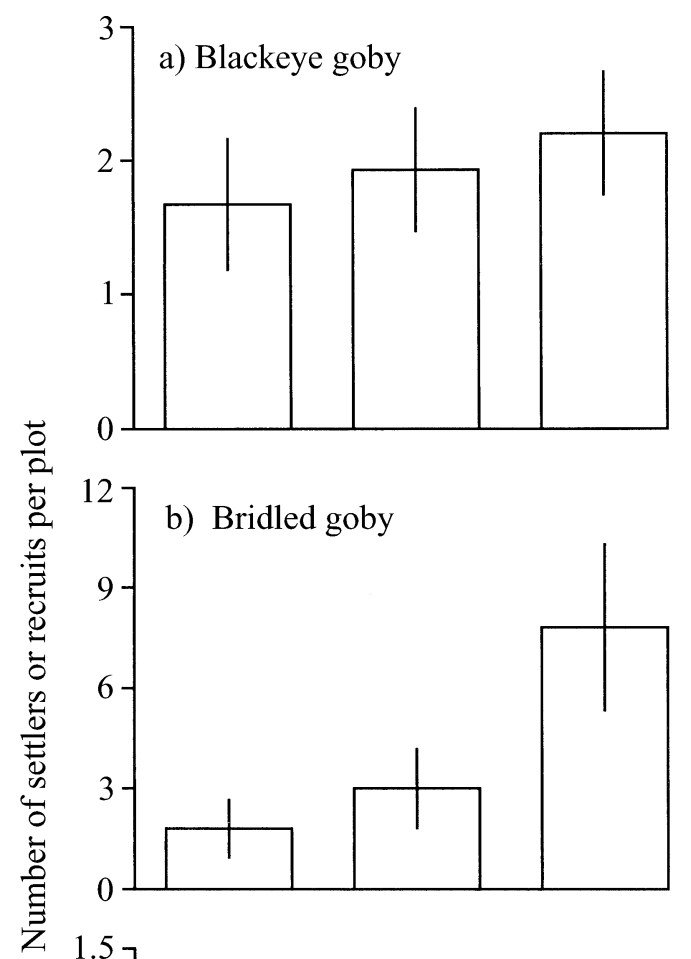

c) Goldspot goby

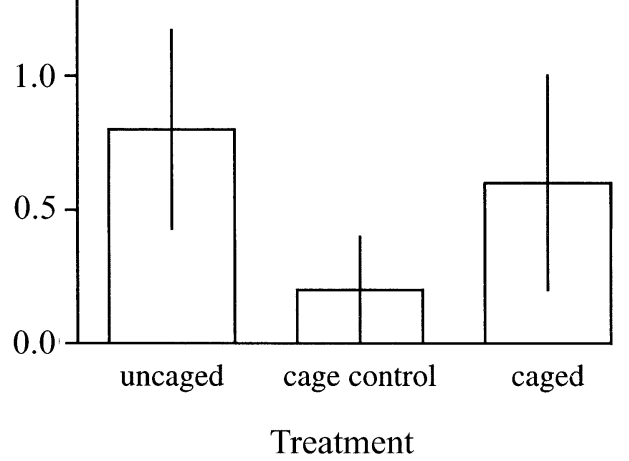

FIG. 1. Results of tests for cage artifacts. The average number of recruits $( \pm 1 \mathrm{SE})$ per plot is shown for each of three treatments. Recruitment was measured daily in bridled and goldspot gobies and summed over $3 \mathrm{wk}$, whereas recruitment was measured only once, after $25 \mathrm{~d}$, in the blackeye goby. For each bar, $n=5$ for bridled and goldspot gobies and 6,15 , and 15 for uncaged, caged, and partially caged treatments for the blackeye goby. See Results: Tests for cage artifacts for results of statistical analyses.

rates of mortality, owing to small-scale patchiness in settlement/recruitment. In other words, since the plots were randomly placed, some likely ended up on good spots and some on bad spots for settlement or recruitment. This natural variation, however, should not have biased our estimates of the mean rates of mortality, but it did lead to a few estimates of mortality that were negative, which is biologically impossible. In those few cases, we set our estimates of mortality at that station to zero for our tests of density-dependent mortality. 
TABLE 2. Results of analyses of variance for effects of treatment (Table 1: A and B for the blackeye goby, and A-D for the other two gobies), site, and station (nested within site) on the density of young gobies.

\begin{tabular}{lrrrl}
\hline \hline \multicolumn{1}{c}{ Source } & df & Ss & $F$ & $P$ \\
\hline Blackeye goby & & & & \\
Treatment & 1 & 12.61 & 11.94 & $\mathbf{0 . 0 0 9}$ \\
Site $\dagger$ & 1 & 0.12 & 0.13 & 0.73 \\
Station(site) & 8 & 7.04 & 0.83 & 0.60 \\
Treatment $\times$ site & 1 & 0.02 & 0.02 & 0.88 \\
Error & 8 & 8.45 & & \\
Bridled goby & & & & \\
Treatment & 3 & 4.72 & 6.63 & $\mathbf{0 . 0 0 2}$ \\
Site $\dagger$ & 1 & 12.01 & 25.62 & $\mathbf{0 . 0 0 1}$ \\
Station(site) & 8 & 3.75 & 1.98 & 0.09 \\
Treatment $\times$ site & 3 & 0.89 & 1.26 & 0.31 \\
Error & 24 & 5.69 & & \\
Goldspot goby & & & & \\
Treatment & 3 & 1.63 & 2.98 & $\mathbf{0 . 0 5}$ \\
Site $\dagger$ & 1 & 4.92 & 17.94 & $\mathbf{0 . 0 0 3}$ \\
Station(site) & 8 & 2.19 & 1.50 & 0.21 \\
Treatment $\times$ site & 3 & 0.62 & 1.13 & 0.36 \\
Error & 24 & 4.38 & & \\
\hline
\end{tabular}

Note: Data are numbers of recent settlers per plot, summed over the duration of each experiment and transformed to $\ln$ $(x+1)$ to reduce heteroscedasticity and improve normality. Fish in treatments A and B (Table 1) had settled within $24 \mathrm{~h}$ of collection, whereas fish in treatments $C$ and D had settled within a week of collection.

$\dagger$ For the effect "site," station(site) was used as the meansquare error term.

This procedure did not qualitatively affect the results of our tests.

For all analyses, the densities of gobies used were the cumulative total number collected from each replicate over the duration of the experiment. The parametric assumptions of normality and homoscedasticity were evaluated by visual inspection of normal-probability plots of residuals and plots of residuals vs. estimated values, respectively. In ANOVA, violations of the assumption of homoscedasticity were further evaluated with Cochran's test. Where necessary, the data were transformed to $\ln (x+1)$ and they then satisfied both assumptions in all but one case, which is described below.

\section{RESUlts}

\section{Tests for cage artifacts}

For the temperate-zone blackeye goby at Santa Catalina there was little evidence of cage artifacts (Fig. 1a). Although recruitment to partially caged plots was intermediate between uncaged and completely caged plots, this was an insignificant trend (ANOVA, $F_{2,27}=$ $0.29, P=0.75$ ), and the power to detect a difference as large as that found between caged and uncaged treatments in the main experiment was very high $(>99 \%)$. For the tropical bridled goby there was also little evidence of any severe cage artifact (Fig. 1b). There was a slight but nonsignificant enhancement of settlement on partially caged plots vs. uncaged plots (a priori com- parison: $\left.F_{1,8}=1.2, P=0.3\right)$, but this enhancement was very small in comparison to the effect of predators (Fig. 1b). There was no statistical evidence (ANOVA, $F_{2,8}$ $=1.0, P=0.41$ ) of caging artifacts in the goldspot goby, but the power of this test was very low (22\%). We comment further in the Discussion on the potential for cage artifacts to have affected the results of our main experiments.

\section{Effects of predators on settlement and recruitment}

Blackeye goby.-Exposure to predators had an extremely large impact on the density of recently settled blackeye gobies, and the magnitude of the effect did not differ between the two study sites (site $\times$ treatment interaction: $P=0.88$; Table 2; Fig. 2). On average, predators reduced the density of recent settlers by $92 \%$, a highly significant effect $(P=0.009$; Table 2$)$. There was no difference in the average density of recent settlers (caged and uncaged) at the two sites (main effect of site: $P=0.73$; Table 2; Fig. 2), and this lack of difference in densities between sites mirrored the patterns of larval supply, which also did not differ between the two sites (Fig. $3 \mathrm{a}$; $t$ test, $t_{8}=0.62, P=0.55$; data transformed to $\ln (x+1)$ to satisfy the assumption of normality).

Bridled goby.-There was no statistically significant interaction between the effects of treatments and sites in bridled gobies ( $P=0.31$; Table 2 ; Fig. 4a) but our ability to detect an interaction was limited (power $<30 \%$ ). There were, however, significant effects of predation overall (Table 2). Within $24 \mathrm{~h}$ of settlement, predators had reduced the density of recent settlers by $26 \%$, causing a statistically significant difference between treatments $\mathrm{A}$ and $\mathrm{B}$ (a priori comparison: $F_{1,24}$

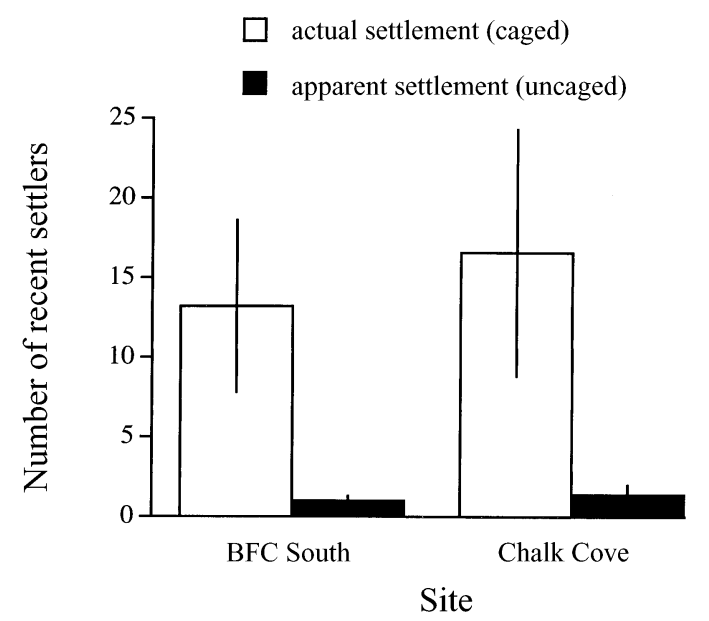

FIG. 2. Densities of recently settled blackeye gobies in two treatments (A and B: exposed to predators or protected from predators; both collected daily) at two sites. Data are means ( $\pm 1 \mathrm{SE})$ of the total number of fish collected daily over $7 \mathrm{~d}$. Only fish judged to be $\leq 1 \mathrm{~d}$ postsettlement at the time of collection are included. For each bar, $n=5$. For statistical comparisons, see Table 2. 


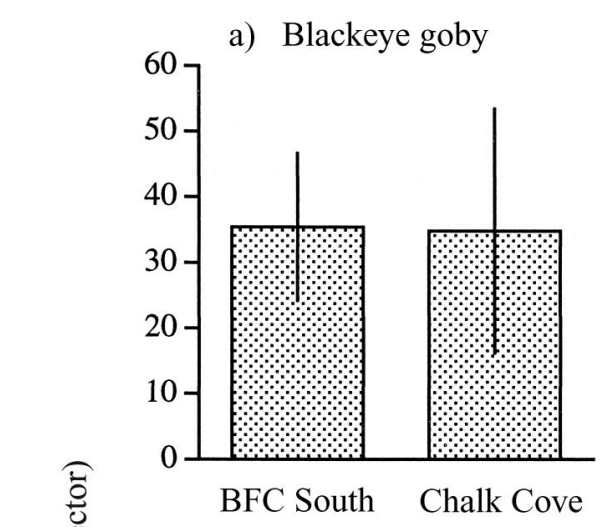

b) Bridled goby

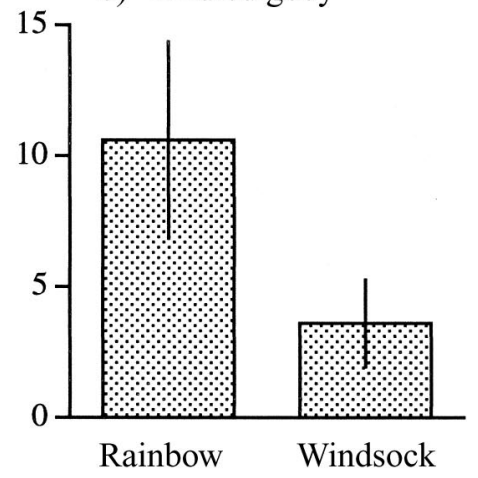

c) Goldspot goby

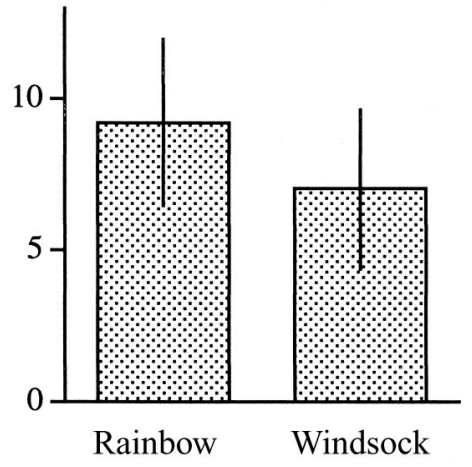

Site

FIG. 3. Estimated patterns of larval supply in the three species of gobies at two sites each. Data are the mean $( \pm 1$ $\mathrm{SE})$ total number of fish $\leq 7 \mathrm{~d}$ old that were collected weekly (over one week-long period for the blackeye goby and over three week-long periods for bridled and goldspot gobies) from standardized larval collectors. For each bar, $n=5$. For statistical comparisons, see Results: Effects of predators on settlement and recruitment.

$=5.7, P=0.025)$. On plots where settlers accumulated for a week, predators caused an even greater reduction in recruitment $(42 \%)$, and this was also statistically significant (a priori comparison comparing treatments $\mathrm{C}$ and D: $\left.F_{1,24}=10.1, P=0.004\right)$.
By comparing actual settlement (treatment A) with recruitment on plots exposed to predators (treatment D), we estimated that mortality of bridled gobies was $58 \%$ in areas exposed to predators for a week (Fig. 4a). This mortality caused a statistically significant difference in the numbers of young bridled gobies collected from treatments $\mathrm{A}$ and $\mathrm{D}$ (a priori comparison: $F_{1,24}=$ $17.7, P=0.0003$ ). The actual weekly rates of mortality, of course, would be higher since the fish collected at the end of each weekly period were of mixed ages, some having just settled and others having settled up to $7 \mathrm{~d}$ earlier. Hence, only a small proportion of the fish on each of these plots was exposed to predators for a full week. By comparing the estimate of the total mortality (58\%) with the estimate of predation over the same weekly period $(42 \%)$, we conclude that predators caused $\sim 72 \%$ of the total mortality of bridled gobies during their first week of reef-bound life. Since many of the recently settled bridled gobies were outside of the cages on "predator-free" plots (see Methods: Main experiment: Experimental design), this figure may actually underestimate the proportion of the total mortality caused by predators.

Averaged over all four treatments, there was a considerable difference in the density of young (settlers and recruits) bridled gobies between sites (main effect of site: $P=0.0001$; Table 2; Fig. 4a). Settlement, for example, was roughly 2.5 times higher at Rainbow Reef than at Windsock Reef. The differences in settlement and recruitment between the sites may be a function of the larval supply rate, which was also $\sim 2.5$ times higher at Rainbow than at Windsock (Fig. 3b). The difference in larval supply between sites, however, was not statistically significant ( $t$ test on data transformed to $\ln [x+1]$ to homogenize variances, $t_{8}=1.99, P=$ 0.08 ), but this test was not particularly powerful (power $=56 \%$ ).

Goldspot goby.-The data for the goldspot goby were heteroscedastic because of one aberrant data point, and no transformation could remedy this problem. ANOVA with that replicate excluded (which successfully homogenized variances) gave qualitatively identical results to ANOVA with the unusual datum included, so we report the results of ANOVA on all data points.

As for the other two species, there was no statistically significant interaction between site and treatment $(P=0.36$; Table 2; Fig. 4b) but the test was weak (power $<30 \%$ ). No effect of predators was detected within $24 \mathrm{~h}$ of settlement (a priori comparison of treatments A and B: $F_{1,24}=0.80, P=0.38$ ). Within a week of settlement, however, predators caused a significant $28 \%$ reduction in recruitment (a priori comparison of treatments C and D: $F_{1,24}=8.14, P=0.009$; Fig. $4 b$ ). Predators apparently caused virtually all of the mortality of goldspot gobies during their first week of reefbound life. Comparing recruitment on plots exposed to predators (treatment $\mathrm{D}$ ) with actual settlement (treat- 

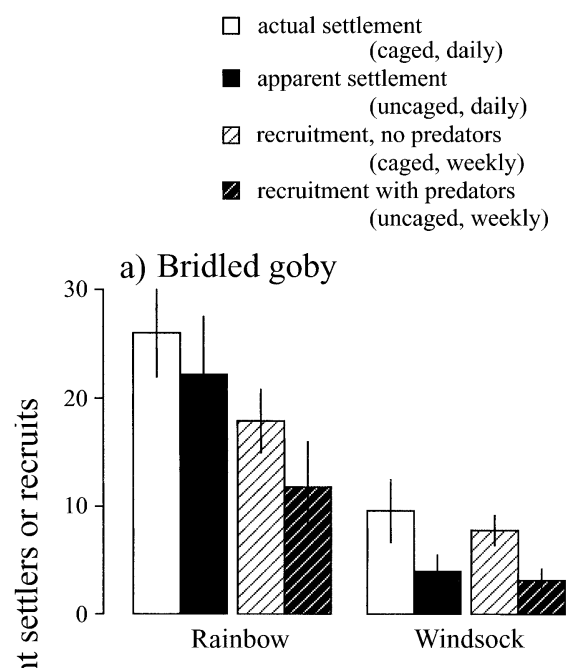

b) Goldspot goby

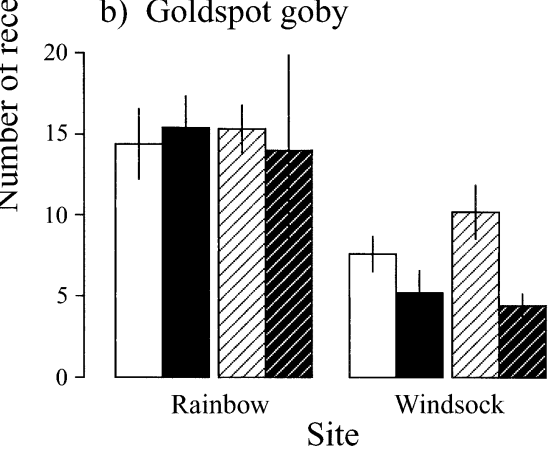

FIG. 4. Patterns of settlement and recruitment in bridled and goldspot gobies that were protected from or exposed to predators (treatments A-D) at two sites. Recently settled gobies were collected at two frequencies: daily or weekly. For daily collections, only those fish judged to be $\leq 1 \mathrm{~d}$ postsettlement at the time of collection are included, and for weekly collections, only those fish judged to be $\leq 7 \mathrm{~d}$ postsettlement at the time of collection are included. Shown is the average per plot $( \pm 1 \mathrm{SE})$ of the total number of fish that were collected daily or weekly over three 7-d periods. For each bar, $n=5$. For statistical comparisons, see Table 2 and Results: Effects of predators on settlement and recruitment.

ment A) produced an estimate of $26 \%$ mortality in the first week after settlement, which is virtually identical to our estimate of predation over the same period, suggesting that all mortality was caused by predation.

The density of young goldspot gobies (settlers and recruits) differed significantly between the two sites (main effect of site: $P=0.003$ : Table 2; Fig. 4b). Greater densities of young gobies were present at Rainbow than at Windsock Reef. Our index of larval supply did not differ among the two sites ( $t$ test, $t_{8}=0.58, P$ $=0.58$ ), but a lack of test power (power $<10 \%$ ) compromised our ability to detect a link between larval supply and settlement.

\section{Are spatial patterns of recruitment and settlement correlated?}

The extent to which predators distorted spatial patterns of settlement varied among the three species, with the distortion generally increasing with the intensity of predation. For the blackeye goby, the species that suffered the greatest predation, settlement on caged and uncaged plots was uncorrelated even when settlers were collected daily (Fig. 5a; $r^{2}=0.05, P=0.53$ ). Predation within $24 \mathrm{~h}$ of settlement thus obliterated small-scale spatial variation in settlement, and this was due to the fact that mortality over the 24 -h period between censuses was strongly density dependent (Fig. 6a; $r^{2}=$ $0.66, P<0.005)$.

For the bridled goby, which experienced intermediate levels of predation, apparent settlement (uncaged plots) was moderately well predicted from the actual patterns of settlement (Fig. 5b; $r^{2}=0.52, P=0.018$ ). The ability to predict patterns of recruitment from patterns of settlement (treatment A) after an additional 6 $\mathrm{d}$ of exposure to predators (treatment D) was just as strong (Fig. 5c; $r^{2}=0.59, P=0.010$ ). Postsettlement mortality, mainly predation, failed to completely obscure small-scale spatial variation in settlement of bridled gobies because it was density independent (Fig. $6 \mathrm{~b} ; r^{2}=0.07, P=0.47$ for mortality over a day; and $r^{2}=0.002, P=0.91$ for mortality over a week) and not sufficiently variable.

Of the three species, goldspot gobies suffered least predation within $24 \mathrm{~h}$ of settlement and apparent settlement was tightly related to actual settlement (Fig. $\left.5 \mathrm{~d} ; r^{2}=0.81, P=0.0004\right)$. The relationship between weekly recruitment and actual settlement, however, was much weaker (Fig. 5e; $r^{2}=0.12, P=0.33$ ). The poor fit of this relationship was not, however, due primarily to the effects of predation but rather to small-scale patchiness in recruitment. Specifically, one extraordinary plot that was exposed to predators received many more recruits than any other plot (Fig. 5e). If that plot is excluded, recruitment was moderately well predicted by settlement ( $\left.r^{2}=0.55, P=0.022\right)$. Postsettlement mortality of goldspot gobies did not greatly obscure the actual patterns of settlement because it was density independent, whether measured over a day (Fig. 6c; $r^{2}$ $=0.24, P=0.16)$ or a week $\left(r^{2}=0.00, P=0.97\right)$, and not sufficiently variable to mask patterns of settlement.

Even though predation distorted patterns of settlement to some degree at small spatial scales (stations separated by tens of meters), this was not true at the larger spatial scale we studied. Recruitment to sites separated by hundreds to thousands of meters generally reflected patterns of settlement (Figs. 2 and 4), an assertion supported by the lack of statistically significant interaction between site and treatment terms in the ANOVAs (Table 2). As noted earlier, however, the power of the tests for interactions was low.

\section{Does larval supply drive patterns of settlement and recruitment?}

For two of the three species, larval supply seemed to be the main determinant of patterns of settlement at 


\section{Collected daily}

a) Blackeye goby

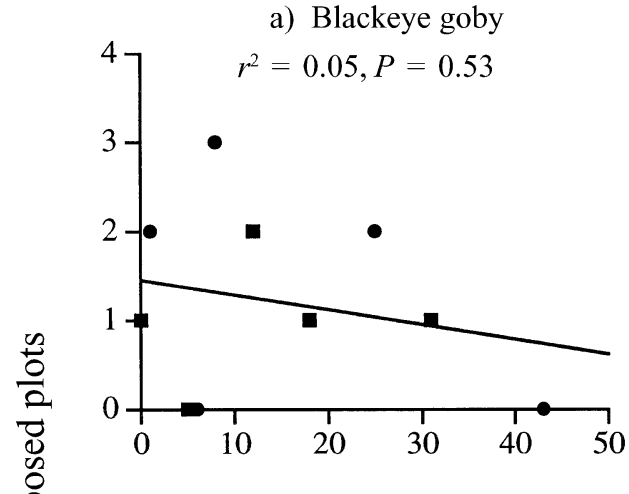

\section{Collected weekly}
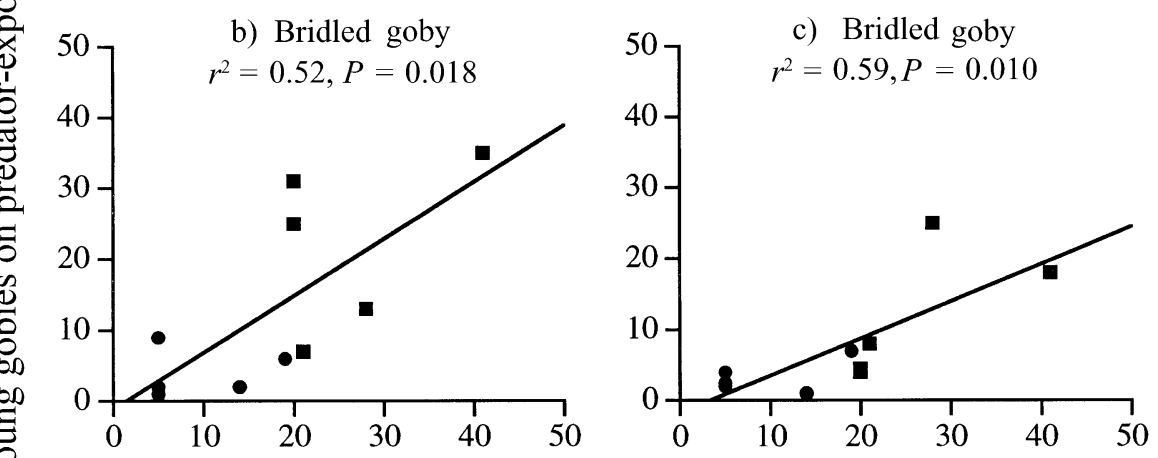

d) Goldspot goby
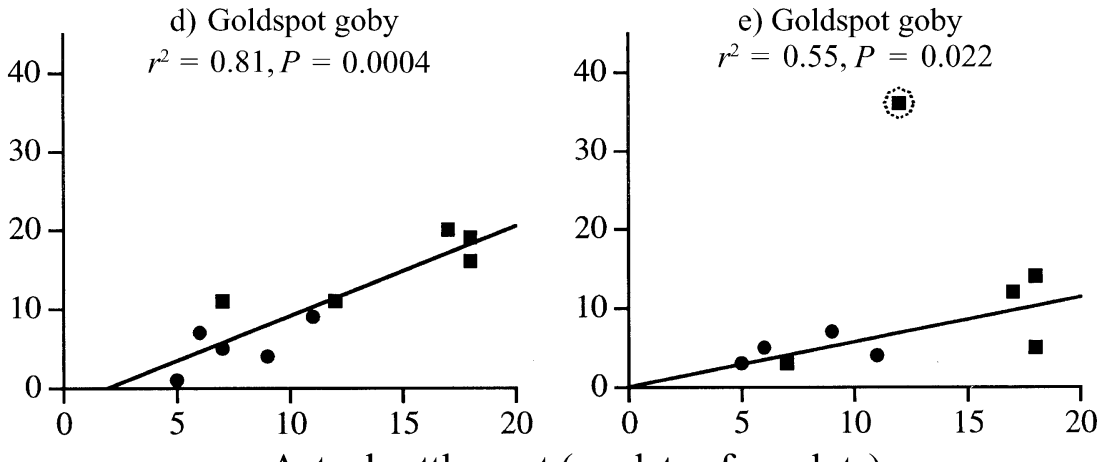

Actual settlement (predator-free plots)

FIG. 5. Relationships between recruitment, measured in the presence of predators (uncaged plots), and settlement, estimated daily in the absence of predators (caged plots). Panels a, b, and d show recruitment measured daily (i.e., fish that had settled within $24 \mathrm{~h}$ ), whereas panels c and e show recruitment measured weekly. Relationships did not differ between sites, so sites (distinguished by the shape of the points) were pooled for the regression, and therefore $n=10$ for each graph. The $r^{2}$ and $P$ values given in panel e are for a regression model that excludes the aberrant point (circled). (For justification and statistics with the point included, see Results: Are spatial patterns of recruitment and settlement correlated?)

both small (tens of meters) and large (hundreds of meters or more) scales. At small scales, actual settlement (treatment A) was well predicted by our index of larval supply (treatment E) in blackeye and bridled gobies $\left(r^{2}\right.$ $=0.64$ in both cases; Fig. 7a,c). The strong relationship between settlement and larval supply in blackeye gobies, however, was eliminated by predators within a day of settlement $\left(r^{2}=0.009\right.$; Fig. 7b). In contrast, predation on bridled gobies during the first $24 \mathrm{~h}$ after settlement only slightly weakened the relationship between apparent settlement and larval supply $\left(r^{2}=0.47\right.$;
Fig. 7d). After one week of exposure to predators, however, the relationship between recruitment and larval supply had largely broken down $\left(r^{2}=0.30\right.$; Fig. 7e). Unlike the other two species, goldspot gobies settled at rates unrelated to larval supply $\left(r^{2}=0.016\right.$; Fig 7f $)$ at small scales. Consequently, neither apparent settlement (uncaged plots) nor recruitment of goldspot gobies was related to larval supply (Fig. $7 \mathrm{~g}, \mathrm{~h}$ ). For none of the three species, then, could we predict small-scale variation in weekly recruitment from our index of larval supply. At the larger spatial scale, however, dif- 

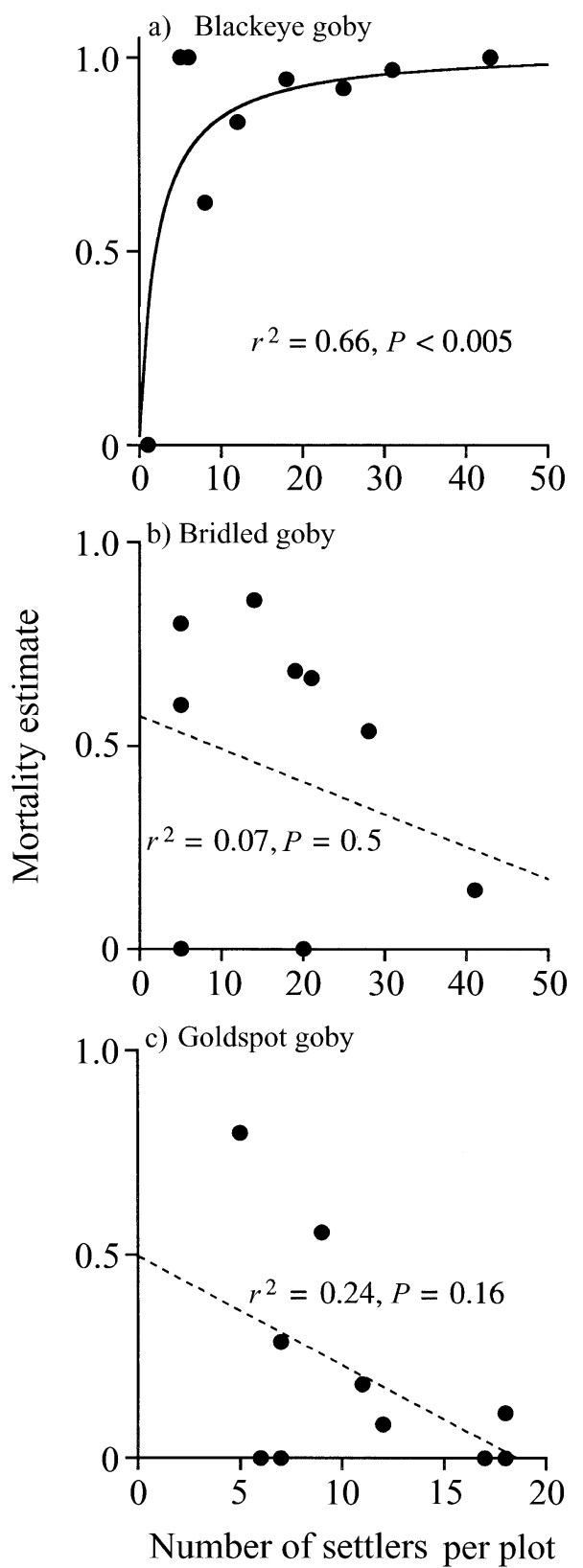

FIG. 6. Tests for density-dependent mortality caused by predators over the first $24 \mathrm{~h}$ after settlement. Mortality was estimated as $1-[($ density of recent settlers on uncaged plots harvested daily)/(density of recent settlers on caged plots harvested daily)]. For more details, see Methods: Main experiment: Testing for density-dependent predation. Sites were pooled, and $n=9$ (one caged plot received no settlers) for graph a, while $n=10$ for graphs b and c. Only for blackeye gobies was there statistical evidence of density-dependent mortality, and this was best described by an asymptotic curve of the form mortality $=\alpha+[(\beta \times$ settlement density $/(1+$ $\beta \times$ settlement density)], where $\alpha$ and $\beta$ are fitted constants, $\alpha$ is the $y$ intercept, and $\beta$ determines the shape of the curve. ferences among the two sites in settlement and recruitment generally reflected patterns of larval supply for all three species (compare Fig. 2 with Fig. 3a, Fig. 3b with Fig. 4a, and Fig. 3c with Fig. 4b).

\section{DISCUSSION}

\section{Possible experimental artifacts}

Caging is a useful technique for testing the effects of predators only if there are no major artifacts caused by the cages themselves (e.g., Virnstein 1978, Dayton and Oliver 1980, Underwood and Denley 1984, Steele 1996). Our tests failed to detect significant cage artifacts, but two factors weaken these tests. First, the experiments on cage artifacts were done separately from the main experiments, and second, our statistical power was too low to detect any but large artifacts. For two species (bridled and blackeye gobies), the density of recent settlers on cage-control plots was intermediate between uncaged and caged plots (Fig. 1a,b). If a more powerful test showed this to be a real difference, this pattern would suggest either that some artifact slightly enhanced settlement to caged plots, or that "control" cages offer partial protection from predators (e.g., Steele 1996), or both. Should such an artifact turn out to be real, its magnitude was small compared to the measured effects of predators. We therefore conclude that caging does provide a reasonable measure of the effect of predation on bridled and blackeye gobies. In the goldspot goby, however, our ability to detect even a large artifact was very low. The nonsignifcant trend we observed was for lower settlement on the cagecontrol than the uncaged plots (Fig. 1c). Should further work show this to be a real difference, it suggests that we would not have confounded predation with cage artifacts. We would, instead, have underestimated the effects of predators on goldspot gobies, making our estimates of predator impacts conservative.

It is also possible that there were cage artifacts in continuous reef habitat where we did our main experiments, but not in the patches of habitat where we tested for cage artifacts. This seems improbable given that the habitat structure was similar (low relief reef), the patches were close to the continuous reef $(10-30 \mathrm{~m}$ away), and the cages used identical, or almost so. Even if a caging artifact affected our measure of settlement, it is unlikely to have affected our test for distortion of spatial patterns of settlement by predation. The only way this test could be biased by a cage artifact is if the type or magnitude of artifact varied spatially. Since all of the experimental plots were placed in the same microhabitat, there is no reason to expect the effect of any artifact to differ among stations or sites. To summarize, there was no evidence that cage artifacts compromised our results, but we cannot rule out this possibility with absolute certainty.

The magnitude of early postsettlement mortality

While keeping the potential for cage artifacts in mind, we believe that these experiments do provide new insight 


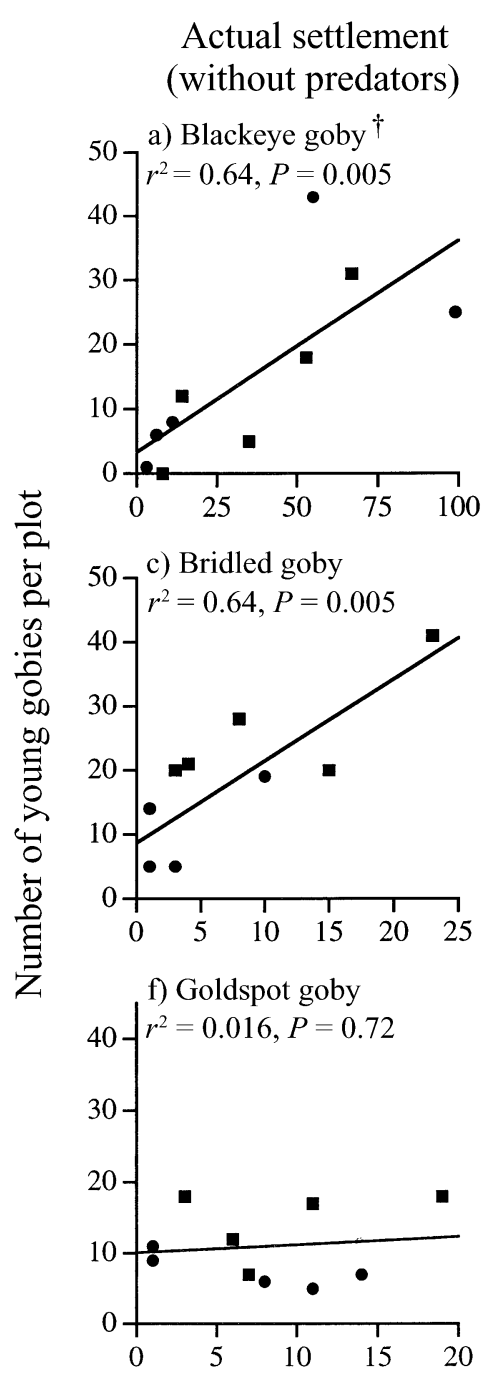

\section{Apparent settlement (with predators)}
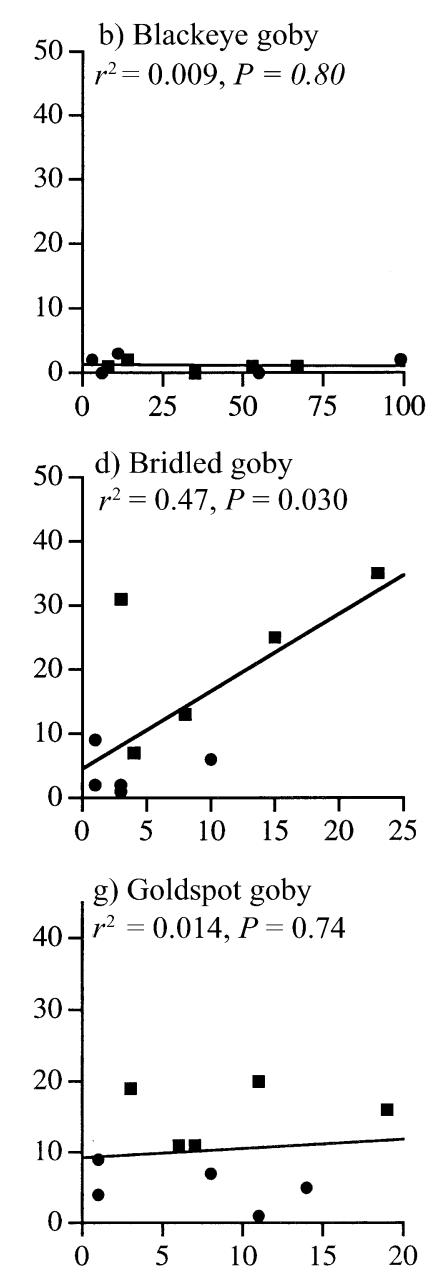

Recruitment (with predators)

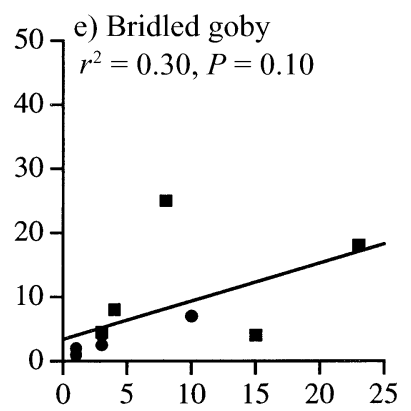

Index of larval supply (no./collector)

FIG. 7. Relationships between larval supply and actual settlement, apparent settlement, and recruitment. Larval supply was estimated as the number of recent settlers harvested weekly from standardized larval collectors (treatment E). Actual settlement (treatment A) was estimated on plots free of predators where recent settlers were harvested daily (panels a, c, and f), apparent settlement (treatment B) on plots exposed to predators where recent settlers were harvested daily (panels b, d, and g), and recruitment (treatment D) on plots exposed to predators and harvested weekly (panels e and $\mathrm{h}$ ).

$\dagger$ The $r^{2}$ and $P$ values given in panel a are for a regression model in which both the independent and dependent variables were transformed to their natural log, which better met the assumption of homogeneity of variance.

\$ The $r^{2}$ and $P$ values given in panel h are for a regression model in which the aberrant point (circled) is excluded. (For justification see Results: Are spatial patterns of recruitment and settlement correlated?) With the point included, $r^{2}=0.003$ and $P=0.87$.

into the effects of predation on reef fish populations. Manipulating predator abundance on coral reefs has been extremely difficult because the most conspicuous predators, piscivorous fishes, tend to be highly mobile. Predator removal is the most desirable way to manipulate predation (Doherty and Sale 1985), but predatorremoval treatments are difficult to maintain in the face of predator movements. In practice, this approach has only been possible for sedentary predators occupying isolated habitat patches (e.g., Carr and Hixon 1995), and even then has not been completely effective (e.g., Caley 1993). We used cages to create predator-free treatments because it is the only practical way to manipulate the abundance of all predatory fishes, both mobile and sedentary species. It is also the only obvious way to manipulate predation in continuous reef habitat, the primary habitat of our study species, and most other reef fishes. The use of cages thus allowed us to study a relatively unexplored period in the lives of many marine organisms, the time just after settlement from the plankton, 
in a more natural habitat and at a larger spatial scale than has been possible previously.

We found that early postsettlement mortality was generally high in our study species, as it is in several other reef fishes (Hixon 1991), marine invertebrates (Hunt and Scheibling 1997), marine algae (Vadas et al. 1992), and terrestrial plants (Crawley 1992). It is well established that seed predators cause much of the mortality suffered by the propagules of terrestrial plants (Crawley 1992), and our results provide some of the first evidence that predators may play a similar role in marine systems. Like studies on seed predation (reviewed in Crawley 1992), our study suggests that the effects of marine predators vary greatly among prey species. Although the apparent rates of predation on the three goby species ranged from 6 to $92 \%$ in the first $24 \mathrm{~h}$ after settlement, predation seemed to be the main cause of death in the first week after settlement in all three species.

We cannot say with complete certainty why new settlers of the three goby species differed in vulnerability to predation. Loss to predation was, however, least in the species with the shortest life-span (goldspot goby) and greatest in the species that lives the longest (blackeye goby), which means that high early postsettlement predation is not a simple consequence of being shortlived. Vulnerability to predators does correspond with how difficult it is for us to detect and capture each species in the field, for reasons that may also make the gobies differentially vulnerable to visually orienting predators. Newly settled goldspot gobies, which suffered the least predation, are small and the most cryptic (being transparent) of the species, have the highest escape velocity when detected, and make the greatest use of crevices for refuge of all three species at this age. Newly settled blackeye gobies, which suffered the most predation, are the largest and slowest of the three species and they are the most conspicuous because they make frequent forays into the water column to capture zooplankton. Of course, the higher rate of predation on the temperate blackeye goby than on the two tropical species may also be due to differences in the predator assemblages in the two systems. There are almost certainly more species that consume small gobies in the Bahamas than at Santa Catalina, but the numerically dominant predator of newly settled gobies in the temperate system (kelp bass) is both very abundant and, in our opinion, a very effective specialist piscivore.

Interpreting differences between species must be tempered by the fact that the intensity of predation also apparently varies within species. In previous experiments using cages to manipulate predation on blackeye gobies, predators reduced blackeye goby density by 24-74\% in the month after settlement (Steele 1997a, Steele et al. 1998), which is a smaller predatory impact than the $92 \%$ reduction in density recorded within 24 $\mathrm{h}$ in this study. These earlier experiments used cages almost identical to the ones used in the present study, but were done on small patches of habitat 10-30 m away from one of the large continuous reefs on which we studied blackeye gobies in this study. The smaller effect of predation in the earlier experiments may be the result of lower densities of predators (mainly kelp bass) being present on the small habitat patches than on the continuous reefs we studied here. An alternative hypothesis, however, is that predation on newly settled blackeye gobies is temporally density dependent (Stewart-Oaten and Murdoch 1990). Predators apparently caused spatially density-dependent mortality of blackeye gobies in this study, meaning that predation increased in areas where settlement was highest (Fig. 6a). Temporal density dependence would be indicated if predation increased at times when settlement was high, perhaps because generalist predators focus their attention on blackeye goby settlers after large pulses of settlement. Estimates of settlement during these experiments indicate that the smallest predator impact $(24 \%)$ did in fact occur when settlement was lowest $\left(0.07 \mathrm{fish} \cdot \mathrm{m}^{-2} \cdot \mathrm{d}^{-1}\right.$ : Steele $\left.1997 a\right)$, an intermediate predator impact $(37-74 \%)$ occurred at intermediate settlement $\left(0.27-1.5 \mathrm{fish} \cdot \mathrm{m}^{-2} \cdot \mathrm{d}^{-1}\right.$ : Steele et al. 1998), and predation had the greatest impact $(92 \%)$ when settlement was high (5.0 fish $\cdot \mathrm{m}^{-2} \cdot \mathrm{d}^{-1}$ : the present study). More rigorous tests for temporally density-dependent predation would be informative because it has the potential to greatly alter temporal patterns of input generated by pulses of settlement.

\section{The consequences of early postsettlement mortality}

It has been argued that variation in propagule input is one of the main processes affecting the dynamics of open marine populations. However, in all but exceptional circumstances (e.g., Stoner 1990, Schmitt and Holbrook 1996), input is measured by counting settlers at some arbitrary point after their transition to benthic existence. These estimates of propagule input are accurate if settlement is a function of larval delivery, and if mortality between settlement and the time of census does not obscure the actual patterns of settlement. Patterns of settlement were generally a function of larval supply in our study. Differences between sites (hundreds to thousands of meters) in settlement mirrored our index of larval supply for all three gobies. For bridled and blackeye gobies, the same was true within sites (stations separated by tens of meters). Small-scale variation in settlement of goldspot gobies was, however, not correlated with our index of larval supply, possibly because of habitat selection by settling larvae (e.g., Raimondi and Morse 2000). Small-scale patterns of settlement were, however, obscured by predation within $24 \mathrm{~h}$ of settlement for one of our study species, the blackeye goby. One of the main implications of this study is, therefore, that protection from predators may often be required to accurately measure settlement. Even measures of settlement based on daily (e.g., Connell 1961, Victor 1986, Sweatman 1988, Raimondi 
1990, Schmitt and Holbrook 1999) or twice-daily (e.g., Sweatman 1985, Booth 1991, Forrester 1999) counts are not immune to this potential bias.

Early postsettlement mortality can distort spatial patterns of settlement when it is density dependent (e.g., blackeye gobies, and see also Steele 1997b, Shima 2001) or when it is density independent and variable (e.g., bridled gobies). For our three study species, the degree of distortion at small spatial scales was greater when early mortality was more severe, regardless of whether mortality was density dependent or independent. We predict that this will be true generally, because as overall mortality increases, the number of survivors (i.e., recruitment) becomes increasingly sensitive to variation in mortality rates. For example, if $50 \%$ of settlers die in their first week, a $10 \%$ increase in mortality (to $60 \%$ ) causes the number surviving to decrease by one-fifth, whereas if mortality over the first week is $80 \%$, a $10 \%$ increase (to $90 \%$ ) reduces the number of survivors by half. Hence, slight variation (stochastic or otherwise) in the rate of mortality in species that suffer extensive mortality can readily distort the relationship between population size and the rate of settlement.

In the present study, the degree to which postsettlement mortality distorted patterns of settlement, however, varied with spatial scale. Considerable distortion of settlement patterns occurred at small scales (stations separated by tens of meters), but at the larger scale we studied (sites separated by hundreds of meters to several kilometers), spatial patterns of settlement remained largely unaltered after a week's worth of mortality had occurred. For all three gobies, then, early mortality varied little between sites compared to variation in settlement at this larger scale. We cannot evaluate the generality of this finding because variability in early postsettlement mortality at large scales has not been studied in other reef fishes. Hunt and Scheibling (1997) concluded from their review of studies on postsettlement mortality in benthic marine invertebrates that rates of mortality were less variable at large scales than small, and this agrees with Menge's (2000) recent findings for barnacles. To some extent, though, these findings are biased because small-scale studies have often explored among-habitat variation, while at the large scale, habitat-related variation has been controlled for. Studies on seed predation have tended to find substantial large-scale variation in rates of seed predation, but these studies have generally focused on among-habitat variation (Crawley 1992). We conclude that better information on how the relative variability of rates of input and loss changes across spatial scales will be needed before we can determine whether propagule input is generally more important to population dynamics as spatial scales increase.

\section{Conclusions}

Our results suggest that high rates of predation just after settlement may render recruitment surveys inac- curate as estimates of true patterns of settlement, at least for small spatial scales. The relationship between recruitment and settlement or larval supply, however, may improve as spatial scale increases, thereby possibly making recruitment surveys useful for estimating rates of propagule input at large scales. In future studies, it will be important to test more rigorously whether the degree to which postsettlement mortality obscures patterns of propagule input declines at larger spatial scales.

This study also indicates that the degree to which early postsettlement mortality distorts patterns of settlement and larval supply will vary among species, even when they are taxonomically and ecologically similar. The species that we studied settle at relatively high densities for reef fishes, and it is possible that taxa that settle densely will suffer greater rates of mortality shortly after settling than will sparsely settling species. Hence, it will be important to measure the magnitude of early postsettlement mortality and its effects on spatial patterns of population density across a range of taxa that vary in their rates of propagule input. By studying a variety of taxa across a range of spatial scales, we will gain a more robust understanding of the degree to which early postsettlement predation, and other sources of mortality, limit and regulate the abundance of marine populations.

\section{ACKNOWLEDGMENTS}

We thank B. Evans, B. Fredericks, A. LaBonte, J. Schinske, H. Sheene, Y. Springer, J. Standish, C. Tran, T. Trejo, and R. Vance for excellent assistance underwater and in the lab. We are also grateful for the fine logistical support provided by the staffs of the Wrigley Institute for Environmental Studies (WIES) and the Caribbean Marine Research Center (CMRC). Discussions and collaboration with T. Anderson, M. Carr, M. Hixon, and R. Vance helped to motivate and focus this work. Comments from J. Witman and two anonymous reviewers improved the final product. Financial support came from a grant to G. E. Forrester from the National Science Foundation (OCE 9618011/0096061), funds from the Perry Foundation, and grants from NOAA-NURP to M. A. Steele and G. E. Forrester (CMRC-01-PRGF-01-01A) and to M. Hixon. M. A. Steele was partially supported by a traineeship from the UC Coastal Toxicology program. This is contribution 218 from WIES and 1344 from CMRC.

\section{Literature Cited}

Anderson, T. W. 1994. The role of macroalgal structure in the distribution and abundance of a temperate reef fish. Marine Ecology Progress Series 113:279-290.

Anderson, T. W., and B. D. Sabado. 1995. Correspondence between food availability and growth of a planktivorous temperate reef fish. Journal of Experimental Marine Biology and Ecology 189:65-76.

Bertness, M. D., S. D. Gaines, E. G. Stephens, and P. O. Yund. 1992. Components of recruitment in populations of the acorn barnacle Semibalanus balanoides (Linnaeus). Journal of Experimental Marine Biology and Ecology 156: 199-215.

Bertness, M. D., S. D. Gaines, and R. A. Wahle. 1996. Winddriven settlement patterns in the acorn barnacle Semibalanus balanoides. Marine Ecology Progress Series 137: 103-110.

Booth, D. J. 1991. The effects of sampling frequency on estimates of recruitment of the domino damselfish Das- 
cyllus albisella. Journal of Experimental Marine Biology and Ecology 145:149-159.

Brown, J. H., and E. J. Heske. 1990. Control of a desertgrassland transition by a keystone rodent guild. Science 250: $1705-1707$.

Caley, M. J. 1993. Predation, recruitment and the dynamics of communities of coral-reef fishes. Marine Biology 117: $33-43$.

Caley, M. J. 1998. Age-specific mortality rates in reef fishes: evidence and implications. Australian Journal of Ecology 23:241-245.

Caley, M. J., M. H. Carr, M. A. Hixon, T. P. Hughes, G. P. Jones, and B. A. Menge. 1996. Recruitment and the population dynamics of open marine populations. Annual Review of Ecology and Systematics 27:477-500.

Carr, M. H. 1994. Effects of macroalgal dynamics on recruitment of a temperate reef fish. Ecology 75:1320-1333.

Carr, M. H., and M. A. Hixon. 1995. Predation effects on early postsettlement survivorship of coral-reef fishes. Marine Ecology Progress Series 124:31-42.

Caselle, J. E., and R. R. Warner. 1996. Variability in recruitment of coral reef fishes: the importance of habitat at two spatial scales. Ecology 77:2488-2504.

Connell, J. H. 1961. Effects of competition, predation by Thais lapillus and other factors on natural populations of the barnacle Balanus balanoides. Ecological Monographs 31:61-104.

Connell, J. H. 1985. The consequences of variation in initial settlement vs. postsettlement mortality in rocky intertidal communities. Journal of Experimental Marine Biology and Ecology 93:11-45.

Crawley, M. J. 1992. Seed predators and plant population dynamics. Pages 157-191 in M. Fenner, editor. Seeds: the ecology of regeneration in plant communities. CAB International, Wallingford, UK.

Dayton, P. K., and J. S. Oliver. 1980. An evaluation of experimental analysis of population and community patterns in benthic marine environments. Pages 93-120 in K. Tenore and B. C. Coull, editors. Marine benthic dynamics. University of South Carolina Press, Columbia, South Carolina, USA.

Doherty, P. J., and P. F. Sale. 1985. Predation on juvenile coral reef fishes: an exclusion experiment. Coral Reefs 4: 225-234.

Eggleston, D. B., and D. A. Armstrong. 1995. Pre- and postsettlement determinants of estuarine Dungeness crab recruitment. Ecological Monographs 65:193-216.

Farrell, T. M., D. Bracher, and J. Roughgarden. 1991. Crossshelf transport causes recruitment to intertidal populations in central California. Limnology and Oceanography 36: 279-288.

Forcucci, D., M. J. Butler, and J. H. Hunt. 1994. Population dynamics of juvenile Caribbean spiny lobster, Panulirus argus, in Florida Bay, Florida. Bulletin of Marine Science 54:805-818.

Forrester, G. E. 1999. The influence of adult density on larval settlement in a coral reef fish, Coryphopterus glaucofraenum. Coral Reefs 18:85-89.

Herrera, C. M., P. Jordano, L. Lopez-Soria, and J. A. Amat. 1994. Recruitment of a mast-fruiting, bird-dispersed tree: bridging frugivore activity and seedling establishment. Ecological Monographs 64:315-344.

Herrnkind, W. F., and M. J. Butler. 1994. Settlement of spiny lobster, Panulirus argus (Latreille, 1804), in Florida: pattern without predictability? Crustaceana 67:46-64.

Hixon, M. A. 1991. Predation as a process structuring coral reef fish communities. Pages 475-508 in P. F. Sale, editor. The ecology of fish on coral reefs. Academic Press, San Diego, California, USA.

Hixon, M. A., and M. H. Carr. 1997. Synergistic predation, density dependence, and population regulation in marine fish. Science 277:946-949.

Hunt, H. L., and R. E. Scheibling. 1997. Role of early postsettlement mortality in recruitment of benthic marine invertebrates. Marine Ecology Progress Series 155:269-301.

Kingsford, M. J., and J. H. Choat. 1986. Influence of surface slicks on the distribution and onshore movements of small fish. Marine Biology 91:161-171.

Menge, B. A. 2000. Recruitment vs. postrecruitment processes as determinants of barnacle population abundance. Ecology 70:265-288.

Milicich, M. J. 1994. Dynamic coupling of reef fish replenishment and oceanographic processes. Marine Ecology Progress Series 110:135-144.

Minchinton, T. E., and R. E. Scheibling. 1991. The influence of larval supply and settlement on the population structure of barnacles. Ecology 72:1867-1879.

Olafsson, E. B., C. H. Peterson, and W. G. J. Ambrose. 1994. Does recruitment limitation structure populations and communities of macro-invertebrates in marine soft sediments?: the relative significance of pre- and postsettlement processes. Oceanography and Marine Biology: An Annual Review 32:65-109.

Paine, R. T. 1966. Food web complexity and species diversity. American Naturalist 100:65-75.

Raimondi, P. T. 1990. Patterns, mechanisms, and consequences of variability in settlement and recruitment of an intertidal barnacle. Ecological Monographs 60:283-309.

Raimondi, P. T., and A. N. C. Morse. 2000. The consequences of complex larval behavior in a coral. Ecology 81:31933211 .

Sale, P. F., and D. J. Ferrell. 1988. Early survivorship of juvenile coral reef fishes. Coral Reefs 7:117-124.

Schmitt, R. J., and S. J. Holbrook. 1996. Local-scale patterns of larval settlement in a planktivorous damselfish-do they predict recruitment? Marine and Freshwater Research 47: 449-463.

Schmitt, R. J., and S. J. Holbrook. 1999. Mortality of juvenile damselfish: implications for assessing processes that determine abundance. Ecology 80:35-50.

Shanks, A. L., J. Largier, L. Brink, J. Brubaker, and R. Hooff. 2000. Demonstration of the onshore transport of larval invertebrates by the shoreward movement of an upwelling front. Limnology and Oceanography 45:230-236.

Shima, J. S. 2001. Regulation of local populations of a coral reef fish via joint effects of density- and number-dependent mortality. Oecologia 126:58-65.

Sponaugle, S., and R. K. Cowan. 1994. Larval durations and recruitment patterns of two Caribbean gobies (Gobiidae): contrasting early life histories in demersal spawners. Marine Biology 120:133-143.

Sponaugle, S., and R. K. Cowan. 1997. Early life history traits and recruitment patterns of Caribbean wrasses (Labridae). Ecology 67:177-202.

Steele, M. A. 1996. Effects of predators on reef fishes: separating cage artifacts from effects of predation. Journal of Experimental Marine Biology and Ecology 198:249-267.

Steele, M. A. 1997a. The relative importance of processes affecting recruitment of two temperate reef fishes. Ecology 78:129-145.

Steele, M. A. 1997b. Population regulation by postsettlement mortality in two temperate reef fishes. Oecologia 112:6474.

Steele, M. A., G. E. Forrester, and G. R. Almany. 1998. Influences of predators and conspecifics on recruitment of a tropical and a temperate reef fish. Marine Ecology Progress Series 172:115-125.

Stewart-Oaten, A., and W. W. Murdoch. 1990. Temporal consequences of spatial density dependence. Journal of Animal Ecology 59:1027-1045. 
Stoner, A. W., P. A. Pitts, and R. A. Armstrong. 1996. Interaction of physical and biological factors in the largescale distribution of juvenile queen conch in seagrass meadows. Bulletin of Marine Science 58:217-233.

Stoner, D. S. 1990. Recruitment of a tropical colonial ascidian: relative importance of pre-settlement vs. postsettlement processes. Ecology 71:1682-1690.

Sweatman, H. P. A. 1985. The timing of settlement by larval Dascyllus aruanus: some consequences for larval habitat selection. Pages 367-371 in Proceedings of the Fifth International Coral Reef Congress (Tahiti). Antenne Museum-Ephe, Moorea, French Polynesia.

Sweatman, H. P. A. 1988. Field evidence that settling coral reef fish larvae detect resident fishes using dissolved chemical cues. Journal of Experimental Marine Biology and Ecology 124:163-174.

Thorrold, S. R., J. M. Shenker, E. Wishinski, R. Mojica, and E. D. Maddox. 1994. Larval supply of shorefishes to nursery habitats around Lee Stocking Island, Bahamas. I. Small-scale distribution patterns. Marine Biology 118:555566.

Tolimieri, N. 1995. Effects of microhabitat characteristics on the settlement and recruitment of a coral reef fish at two spatial scales. Oecologia 102:52-63.

Underwood, A. J. 1997. Experiments in ecology: their logical design and interpretation using analysis of variance. Cambridge University Press, Cambridge, UK.
Underwood, A. J., and E. J. Denley. 1984. Paradigms, explanations, and generalizations in models for the structure of intertidal communities on rocky shores. Pages 151-180 in D. R. Strong, D. Simberloff, L. G. Abele, and A. B. Thistle, editors. Ecological communities: conceptual issues and the evidence. Princeton University Press, Princeton, New Jersey, USA.

Vadas, R. L., S. Johnson, and T. A. Norton. 1992. Recruitment and mortality of early postsettlement stages of benthic algae. British Phycological Journal 27:331-351.

Victor, B. C. 1986. Larval settlement and juvenile mortality in a recruitment-limited coral reef fish population. Ecological Monographs 56:145-160.

Virnstein, R. W. 1978. Predator caging experiments in soft sediments: caution advised. Pages 261-273 in M. L. Wiley, editor. Estuarine interactions. Academic Press, New York, New York, USA.

Warner, R. R., and T. P. Hughes. 1988. The population dynamics of reef fishes. Pages 149-155 in Proceedings of the Sixth International Coral Reef Symposium, Townsville, Australia. Volume 1. Executive Committee, Townsville, Australia.

Wenny, D. G. 2000. Seed dispersal, seed predation, and seedling recruitment of a neotropical montane tree. Ecological Monographs 70:331-351.

Winer, B. J., D. R. Brown, and K. M. Michels. 1991. Statistical principles in experimental design. Second edition. McGraw-Hill, New York, New York, USA. 